\title{
Slim-Prim: an integrated data system for clinical and translational research
}

\author{
Teeradache Viangteeravat ${ }^{1}$, Ian M Brooks ${ }^{1}$, Somchan Vuthipadadon ${ }^{1}$, Emin Kuscu', Naga Nagisetty ${ }^{1}$ Ebony Smith', \\ Ramin Homayouni ${ }^{2}$, Chanchai S McDonald ${ }^{1 *}$
}

From UT-ORNL-KBRIN Bioinformatics Summit 2010

Cadiz, KY, USA. 19-21 March 2010

\section{Background}

Translational science provides opportunities for basic and clinical research scientists to address healthcare problems collaboratively. However, data from different research domains present disparate storage and accessibility issues due to data heterogeneity and size. Increasingly, centralized data storage and maintenance options are utilized to overcome these problems. The Biomedical Informatics Unit of the UT-CTSI has developed a scalable and modular integrated data system (IDS), the Slim-Prim system (Scientific Laboratory \& Patient-care Research Information Management), to address these issues.

\section{Materials and methods}

Slim-Prim is a relational database acting as a clinical trial data management interface and archival data repository. Data access is provided through userfriendly web-applications. Slim-Prim provides secure, centralized data storage and analytic services to clinical and basic science researchers at UTHSC. Data integrity is monitored via powerful built-in analytic tools. The system is customizable, allowing batch import of large datasets and integration with ongoing studies. Export functions allow data to be extracted to third party analysis software. Importantly, administrative tools allow the PI of any dataset to control access to their data. Collaboration is an essential aspect of translational research, and Slim-Prim fosters a collaborative environment via HIPAA compliant data sharing via secure web applications.

* Correspondence: Chanchai@uthsc.edu

'Biomedical Informatics Unit, University of Tennessee Health Science Center, Memphis, TN 38163, USA

\section{Author details}

'Biomedical Informatics Unit, University of Tennessee Health Science Center, Memphis, TN 38163, USA. ${ }^{2}$ Department of Biology, University of Memphis, Memphis, TN 38152, USA.

Published: 23 July 2010

\section{doi:10.1186/1471-2105-11-S4-P5}

Cite this article as: Viangteeravat et al:: Slim-Prim: an integrated data system for clinical and translational research. BMC Bioinformatics 201011 (Suppl 4):P5.
Submit your next manuscript to BioMed Central and take full advantage of:

- Convenient online submission

- Thorough peer review

- No space constraints or color figure charges

- Immediate publication on acceptance

- Inclusion in PubMed, CAS, Scopus and Google Scholar

- Research which is freely available for redistribution

Submit your manuscript at www.biomedcentral.com/submit
C Biomed Central 